\title{
Influence of rugby injuries on players' subsequent health and lifestyle: beginning a long term follow up
}

\author{
A J Lee, W M Garraway, W Hepburn, R Laidlaw
}

\begin{abstract}
Objectives-To describe the current rugby playing status of a cohort of 1169 men who had previously participated in an epidemiological survey of rugby injuries during the 1993-1994 season, and assess the consequences of rugby injuries sustained. Methods-In May 1998, 911 (78\%) men completed a questionnaire reporting their current involvement in rugby and the influence that the $324(71 \%)$ injuries they had sustained four years earlier had since had on their health and wellbeing.

Results-The most common reasons given by the $390(43 \%)$ ex-players for ceasing to play rugby were family $(10 \%)$, employment $(25 \%)$, and an injury sustained while playing rugby $(26 \%), 80 \%$ of which were dislocations, strains, and sprains, mainly to the knee (35\%), back (14\%), and shoulder (9\%). A significantly ( $\chi^{2}$ test 21.7 , df $\left.=1, \mathbf{p}<0.001\right)$ higher proportion of current players $(90 \%)$ undertook (non-rugby) sporting activities compared with ex-players $(78 \%)$. Few ex-players undertook coaching (12\%) and refereeing $(2 \%)$. Only $22(9 \%)$ men reported significant negative effects to employment, family life, and health up to mid-1998 from injuries that occurred during the 1993-1994 season, although the impact on their lifestyle had been substantial in some cases.
\end{abstract}

Conclusions-With the recent increase in the incidence of dislocation, strain, and sprain injuries in rugby football, the findings of this follow up could have a great impact on the game in the future. Although this survey has shown that, so far, only a small proportion of players suffer significant effects of rugby injuries, four years is not long enough to assess the long term effects. This cohort of rugby players need to be followed up for at least a further 20 years to determine whether there is a higher incidence of subsequent degenerative joint disease or other long term sequelae to injuries sustained while playing rugby.

(Brf Sports Med 2001;35:38-42)

Keywords: follow up; injury; knee; lifestyle; rugby union; epidemiology

Correspondence to: Miss A J Lee, Medical Statistics Unit, Public Health Sciences, University of

Edinburgh, Medical School, Teviot Place, Edinburgh EH8 9AG, Scotland, UK

Mandy.Lee@ed.ac.uk

Accepted 6 September 2000 pants, these benefits far outweigh any potential adverse effects that may occur. ${ }^{1-3}$ People need to exercise on a regular basis throughout life to reap the benefits, ${ }^{1}$ but older people are less likely to participate in fitness and sporting activities. ${ }^{4}$ It is important to know why people cease to participate in sporting and physical activities, and what incentives can be offered to encourage them to become involved again. It is also essential to recognise that adverse effects as a result of exercise may occur. Injury rates are high in rugby union, ${ }^{5-10}$ and many rugby injuries occur that involve muscles, ligaments, and joints, ${ }^{5}$ which could result in subsequent degenerative disease. ${ }^{11-13}$ The effects of serious spinal cord injuries sustained while playing rugby have been reported, ${ }^{14}{ }^{15}$ and, after changes to the laws of the game, the overall number of such injuries has been reduced in most countries, ${ }^{16}{ }^{17}$ with the exception of South Africa. ${ }^{18}$ However, these injuries are rare ${ }^{17}$ In addition, these studies only include injuries involving the spinal cord. Ten severe neck injuries without spinal cord involvement may occur for each spinal cord injury. ${ }^{18}$ It is necessary to examine the long term effects of these and other more common rugby injuries. Degenerative joint disease may take at least 20 years to develop, ${ }^{19}$ so it is necessary to follow up cohorts of players over a long period of time. We began this process by studying the consequences of injuries sustained in a cohort of rugby players in the 1993-1994 season four years after they occurred. ${ }^{5}$

\section{Methods}

QUESTIONNAIRE COMPLETED BY ALL MEN

Two of the 1169 men who participated in a prospective survey of rugby injuries in the Border Reivers District of the Scottish Rugby Union (SRU) conducted during the 19931994 season $^{5}$ had died. Another player was not contacted after a subsequent serious cervical injury sustained while playing rugby, ${ }^{8}$ but information about his status was obtained from others. Three players had returned to New Zealand and could not be contacted. The remaining 1163 men were sent postal questionnaires in April 1998, asking their current participation in rugby and other sporting activities. Men who no longer played rugby were asked to provide reasons why they had stopped and whether they had any current involvement with rugby. Reminder letters were sent two weeks later, and men who failed to respond were contacted by telephone. A total of $911(78 \%)$ questionnaires were completed, including 445 by men who had participated in a repeat prospective cohort study during the 1997-1998 season. ${ }^{8}$ 
INJURY QUESTIONNAIRE(S) COMPLETED BY MEN INJURED DURING 1993-1994 SEASON

A total of 357 (out of the 1163) players, who had 508 injury episodes recorded during the 1993-1994 season, ${ }^{5}$ were sent injury questionnaire(s). For recurrent or similar injuries for which it would have been difficult for the player to distinguish the effects - for example, when a strained shoulder and a dislocated shoulder occurred on two separate occasions during the 1993-1994 season, or bruising and swelling to the knee occurred on one occasioncompletion of only one injury questionnaire was requested. Injuries were combined on 56 forms. For single injury episodes where more than one distinct injury - for example, concussion and a dislocated shoulder-had been sustained, completion of one injury questionnaire for each distinct injury was necessary. This resulted in 458 injury questionnaires from the 508 injury episodes. All forms stated the nature and date(s) of the injury or injuries sustained. Men were asked if they had had a recurrence of the specific injury or treatment for it since June 1994. They were asked if the injury had affected ("no effect at all", "temporary effect", or "significant effect") their education or studies, employment or career prospects, personal or family life, and health or general fitness, and their rugby playing career ("no effect at all", "not playing at same level", "stopped temporarily", or "stopped completely"). These response categories were not defined for the players. In total, $258(72 \%)$ injured players returned $324(71 \%)$ injury forms, but one player with two injury questionnaires had no recurrences from either injury and did not complete the remaining questions.

STATISTICAL ANALYSIS

Playing status and players' age on 1 May 1998 was used in the analyses. Each injury questionnaire was classified into one of five categories of injury. ${ }^{5}$ (ICD codings for the site and nature of each injury can be obtained from the authors.) For the injury forms referring to multiple injuries when there was a discrepancy in category, classification was based on the injury classified as most severe during the 1993-1994 season. $\chi^{2}$ test and $\chi^{2}$ test for trend were used to assess differences in response rate between different groups of players. Mann-Whitney U test was used to compare the age of players, and confidence intervals were calculated for the difference in median age. ${ }^{20}$
COMPARISON OF SURVEY RESPONDERS AND NON-RESPONDERS

The survey response rate was not affected by the number of injury forms that the player was asked to complete ( $\chi^{2}$ test for trend grouping three to five injury forms: $2.0, \mathrm{df}=1, \mathrm{p}=0.16)$, but differed significantly ( $\chi^{2}$ test: $144.3, \mathrm{df}=1$, $\mathrm{p}<0.001)$ between players who participated in the repeat prospective survey ${ }^{8}(96 \%)$ and those who did not $(66 \%)$. Postal responders ( $\mathrm{n}=$ 450) were older (Mann-Whitney U test; $\mathrm{p}<0.001,95 \%$ confidence interval for difference in median age 1-2 years) than telephone responders $(n=461)$. They were also more likely to be a member of a rugby club $(85 \% v$ $75 \% ; \chi^{2}$ test: $\left.15.0, \mathrm{df}=1, \mathrm{p}<0.001\right)$, still play rugby $\left(62 \%\right.$ v $53 \% ; \chi^{2}$ test: $7.3, \mathrm{df}=1, \mathrm{p}=$ 0.007), or have stopped playing following a rugby injury rather than for other reasons $(50 \%$ v $27 \% ; \chi^{2}$ test: $\left.20.7, \mathrm{df}=1, \mathrm{p}<0.001\right)$ than telephone responders.

\section{Results}

CURRENT PLAYING STATUS AND REASONS MEN STOPPED PLAYING RUGBY

In May 1998, although 729 (80\%) men were still rugby club members, only 521 (57\%) continued to play rugby. There was a strong relation between current rugby playing status and participation in other sporting activities $\left(\chi^{2}\right.$ test: $21.7, \mathrm{df}=1, \mathrm{p}<0.001)$. Some $90 \%$ of current players participated in other sporting activities compared with $78 \%$ of ex-players.

The 390 ex-players provided 566 reasons for ceasing to play rugby; sustaining a rugby injury and work commitments were predominant reasons regardless of age (table 1). Rugby injuries that caused retirement from the game were dislocation, strain, or sprain injuries to the knee (35\% of all injuries), back (14\%), shoulder $(9 \%)$, neck $(8 \%)$, ankle and foot $(8 \%)$, and hip and thigh $(6 \%)$. Fractures caused only $11(8 \%)$ men to stop playing, and six (4\%) men stopped as a result of being concussed. Most players had sustained the injury only recently $(n=140$; $43 \%$ stopped playing the same month and $12 \%$ one or two months later), but one quarter had first sustained the injury two or more years ago.

INVOLVEMENT WITH THE GAME OF RUGBY AND INCENTIVES TO RETURN

Ex-players involved directly with the game (club official, coach, or referee) were significantly older than those not involved (MannWhitney U test, $\mathrm{p}<0.001,95 \%$ confidence

Table 1 Why men stopped playing rugby according to age group (in years)

\begin{tabular}{|c|c|c|c|c|c|c|c|c|c|c|}
\hline \multirow[b]{2}{*}{ Reason for stopping } & \multicolumn{2}{|c|}{$<20$} & \multicolumn{2}{|c|}{$20-24$} & \multicolumn{2}{|c|}{$25-29$} & \multicolumn{2}{|c|}{$\geqslant 30$} & \multicolumn{2}{|c|}{ Total } \\
\hline & No & $\%$ & No & $\%$ & No & $\%$ & No & $\%$ & No & $\%$ \\
\hline Feels too old to play & 0 & 0 & 0 & 0 & 1 & 1 & 46 & 17 & 47 & 8 \\
\hline Rugby injury & 13 & 19 & 32 & 28 & 39 & 38 & 61 & 22 & 145 & 26 \\
\hline Other injury & 4 & 6 & 6 & 5 & 6 & 6 & 13 & 5 & 29 & 5 \\
\hline Employment & 10 & 14 & 38 & 33 & 29 & 28 & 64 & 23 & 141 & 25 \\
\hline Studies & 16 & 23 & 12 & 10 & 3 & 3 & 3 & 1 & 34 & 6 \\
\hline Family & 2 & 3 & 4 & 3 & 9 & 9 & 42 & 15 & 57 & 10 \\
\hline Disillusion with game (playing) & 11 & 16 & 5 & 4 & 1 & 1 & 4 & 1 & 21 & 4 \\
\hline Disillusion with game (system) & 3 & 4 & 6 & 5 & 3 & 3 & 9 & 3 & 21 & 4 \\
\hline Fear of injury & 1 & 1 & 1 & 1 & 3 & 3 & 16 & 6 & 21 & 4 \\
\hline Other reasons & 10 & 14 & 12 & 10 & 10 & 10 & 18 & 7 & 50 & 9 \\
\hline Total number of reasons & 70 & 100 & 116 & 100 & 104 & 100 & 276 & 100 & 566 & 100 \\
\hline Number of players & 57 & & 90 & & 73 & & 170 & & 390 & \\
\hline
\end{tabular}


Table 2 Ex-players' involvement in the game of rugby

\begin{tabular}{|c|c|c|c|c|c|c|}
\hline \multirow{2}{*}{$\begin{array}{l}\text { Age on 1/8/97 } \\
\text { (years) }\end{array}$} & \multicolumn{6}{|c|}{ Involvement in game of rugby: } \\
\hline & None & Club official & Coach & Referee & Other* & Totalt \\
\hline$<16$ & 43 & 0 & 2 & 0 & 12 & 57 \\
\hline $16-19$ & 43 & 2 & 3 & 2 & 23 & 73 \\
\hline $20-24$ & 38 & 6 & 0 & 2 & 23 & 69 \\
\hline $25-29$ & 39 & 11 & 15 & 1 & 33 & 99 \\
\hline $30-34$ & 23 & 5 & 17 & 1 & 12 & 58 \\
\hline$\geqslant 35$ & 8 & 5 & 8 & 3 & 4 & 28 \\
\hline Total & 194 & 29 & 45 & 9 & 107 & 384 \\
\hline
\end{tabular}

^Includes those players who play occasionally or have only stopped playing temporarily. †Six ex-players did not provide details of their involvement in the game.

interval for difference in median age: 6-10 years) as illustrated in table 2 . Twenty seven $(7 \%)$ ex-players expressed dissatisfaction with the way professionalism had been introduced, internal club politics, or the increasing emphasis on successful match results rather than the enjoyment of the game. Few ex-players expressed an interest in the following incentives to return to the game of rugby again: educational programmes (16), refresher programmes (13), monetary rewards (10), or easier access to international rugby match tickets (12). Thirty seven ex-players indicated that other "incentives" would encourage them to become involved, including a change in the structure of the game (20) and having more leisure time (10).

TREATMENT OF RUGBY INJURIES SUSTAINED DURING THE 1993-1994 SEASON

Players reported that $77 \%$ of their injuries had not had any recurrences. One quarter (84/322) of all injuries had received treatment since June 1994. Treatment included visits to the general practitioner (31), physiotherapy (54), attendance at outpatient clinics (25), and hospital admission (21).

CONSEQUENCES OF RUGBY INJURIES SUSTAINED DURING 1993-1994 SEASON

Twenty three (9\%) men stopped playing rugby completely, and a further $27(10 \%)$ men played at a lower team level after their injury or injuries. Ninety one $(35 \%)$ men reported temporary or significant effects on education, employment, family life, or health and general fitness from their 95 injuries (table 3). Twenty two $(9 \%)$ players reported at least one significant negative effect. In addition, one man reported a significant positive effect; he became motivated to play again. The 22 negative effects included difficulties with employment (4),

Table 3 Number of injuries which were sustained during the 1993-94 season which subsequently caused temporary or significant effects to players' lifestyle

\begin{tabular}{|c|c|c|c|c|c|}
\hline \multirow[b]{3}{*}{ Type of injury } & \multirow[b]{3}{*}{$N^{\star}$} & \multicolumn{4}{|c|}{$\begin{array}{l}\text { Any effects on education, employment, family } \\
\text { life or health and general fitness }\end{array}$} \\
\hline & & \multicolumn{2}{|c|}{ Temporary } & \multicolumn{2}{|c|}{ Significant } \\
\hline & & $N^{*}$ & $\%$ & $N^{*}$ & $\%$ \\
\hline Concussion & 18 & 5 & 28 & 1 & 6 \\
\hline Fractures & 34 & 10 & 29 & $4 \dagger$ & 12 \\
\hline Dislocations, strains and sprains & 178 & 45 & 25 & 14 & 8 \\
\hline Lacerations and contusions & 69 & 6 & 9 & 2 & 3 \\
\hline Other injuries & 23 & 6 & 26 & 2 & 9 \\
\hline Overall & 322 & 72 & 22 & 23 & 7 \\
\hline
\end{tabular}

^Number of injuries not number of players.

tOne of these effects was positive; the player became motivated to play again. restriction (6) or cessation (4) of previous sporting activity, and continuing pain or stiffness (4).

\section{Discussion}

This is the first long term follow up begun in a representative cohort of rugby union players. Of the 390 ex-players, 145 (37\%) stated that they had ceased playing because of an injury sustained while playing rugby. Some $22(9 \%)$ players suffered significant negative effects on employment, family life, and/or health after injuries sustained four years earlier.

The difference in the response rate between players who did and did not participate in the repeat prospective survey ${ }^{8}$ could have resulted in an overestimation of the proportion of men who still played rugby. The effect was present in a comparison of early (postal) and late (telephone) responders. Postal responders were also more likely than telephone responders to have stopped playing rugby because of a rugby injury (rather than for other reasons). This could have resulted in an overestimation of the proportion of men who gave up because of a rugby injury. However, the number of injuries sustained during the 1993-1994 season did not influence the response rate and the overall response rate for the survey was high $(78 \%)$.

Memory recall is another potential problem with the survey, particularly so because minor injuries, such as bruising and minor lacerations, were included. However, it was assumed that players would remember injuries that had caused them significant effects. Attempts were made to minimise this problem by clearly stating the nature and date(s) of injury or injuries sustained during the 1993-1994 season on each injury form. In addition, some injury forms related to multiple injury episodes when the player sustained similar injuries, and it was expected that he would be unable to distinguish the longer term effects. This may have affected players' interpretation of the effects on their injury. However, grouping of injuries occurred for only $12 \%$ of returned forms, and injuries were grouped into categories for analysis. No definition of the response categories on the injury form was provided, and responses were therefore dependent on interpretation by the individual player, which would be influenced by the player's employment, leisure activities, and family commitments.

It is likely that the long term effects of rugby injuries would be influenced by the type and timing of the initial treatment received, and by other factors, such as whether players attended a comprehensive physical training programme during recovery. ${ }^{21}$ Although we did collect information about medical treatment received during the 1993-1994 season, we would not have been able to state from that information whether players' injuries were being managed appropriately.

Four in ten men had stopped playing rugby in the four years since the 1993-1994 season. Although many men stopped playing rugby because of age and commitments to employment, education, and family, there was a relatively high proportion of men who had 
sustained a rugby injury or feared sustaining a rugby injury or were disillusioned with the game. Furthermore, few of the ex-players went on to coach rugby $(12 \%)$ and an even smaller proportion $(2 \%)$ became referees. Many explayers are taking a passive rather than an active role in rugby, remaining club members but not undertaking coaching or refereeing. This may reflect a lack of free time. However, as $45 \%$ of ex-players in their 30 s became directly involved with the game compared with $21 \%$ of ex-players in their 20 s, lack of interest and confidence in the game may be more important factors. Although a high proportion $(78 \%)$ of ex-players undertook other sporting and fitness activities (much higher than in the general population ${ }^{6}$ ), it was a significantly lower proportion than that of current players $(90 \%)$. More youngsters need to be encouraged to participate in sporting activities. ${ }^{22}$ An inadequate number of coaches and referees can only adversely affect the development of youth rugby.

The introduction of professionalism into rugby football has led to an increase in the competitiveness of the amateur game. Although this has had the advantage of increasing the profile of the sport, it has also increased the incidence of injuries and may have led to a decrease in the number of rugby players. ${ }^{8}$ The impact of an increased incidence of rugby injuries could be more pronounced in the future, as $25 \%$ of men retire from the game two or more years after first sustaining their rugby injury. A decrease in the number of players could be compounded in team sports such as rugby; a consistent lack of a full $\mathrm{XV}$ playing team is likely to lead to cancelled matches, which could influence the number of players in opponents' teams, especially if teams regularly play the same opponents. In addition, if substitute players are not available, injured players may be tempted to complete the match in which they were injured, exacerbating the injury. At the lower team levels and in youth rugby, more emphasis on the enjoyment of the game of rugby rather than match success may encourage more ex-players to play again or become coaches and referees. It may also encourage more youngsters to start playing rugby and reduce the incidence of injuries. The social aspect of the game is important to many men; over half of ex-players remain rugby club members.

No other survey has looked at the longer term consequences of specific injuries sustained during rugby training or during a rugby match, with the exception of cervical injuries. ${ }^{14}{ }^{15}$ Few controlled prospective surveys have been conducted in other sports that have examined degenerative disease in athletes, and many factors may be relevant in the development of degenerative joint disease. ${ }^{11}$ Some surveys have reported an accelerated degeneration of the spine in some athletes, ${ }^{13}$ including a survey that found a higher incidence of degenerative disease of the cervical spine in rugby players than in the general population. ${ }^{23}{ }^{24}$ Overuse injuries associated with endurance training or repetitive performances undertaken to improve skill, technique, or power may result in degenerative disease. ${ }^{12}$ The knee joint is commonly afflicted with overuse injuries, ${ }^{25}$ and therefore may be more prone to degenerative disease. This is of concern in rugby football where the incidence of knee injuries is high. ${ }^{8}$ This survey has shown that $13 \%$ of all players who had stopped playing rugby had done so because they had sustained a knee injury, and that $17 \%$ of players who sustained a knee injury during the 1993-1994 season reported significant effects to lifestyle four years later. However, overall, relatively few men (9\%) reported that their injuries were causing significant effects, but four years is too short a period in the natural history of degenerative disease to draw firm conclusions. ${ }^{19}$ It is already clear that rugby injuries have caused significant distress in a small proportion of rugby players in terms of employment and continuing ability to participate in other sporting activities. The higher incidence of rugby injuries recorded after the introduction of professionalism ${ }^{8}$ may result in a more pronounced effect in the future. Steps should be taken to establish cohorts of rugby players and make resources available to follow up players for a much longer period of time. This is the only way to determine whether premature degenerative disease in rugby players is more common than in the general population.

We wish to thank Ms Sue Hutton, our survey coordinator, the research nurses, participating rugby club officials, and the players who participated in the survey. The survey received financial support from a grant provided by the International Rugby Settlement Trust, administered by the Scottish Rugby Union.

1 Report of the Royal College of Physicians. Medical aspects of exercise: benefits and risks. London: The Royal College of Physicians of London, 1991.

2 Scully D, Kremer J, Meade MM, et al. Physical exercise and psychological wellbeing: a critical review. $\mathrm{Br} \mathcal{F}$ Sports Med 1998;32:111-20.

3 Blair SN, Connelly JC. How much physical activity should we do? The case for moderate amounts and intensities of physical activity. Res $Q$ Exerc Sport 1996;67:193-205.

4 Office of National Statistics. Social trends. London: The Stationary Office, 1997.

5 Garraway M, Macleod D. Epidemiology of rugby football injuries. Lancet 1995;345:1485-7.

6 Nicholl JP, Coleman P, Williams BT. The epidemiology of sports and exercise related injury in the United Kingdom.

7 Bird YN, Waller AE, Marshall SW, et al. The New Zealand Rugby Injury and Performance Project. V. Epidemiology of a season of rugby injury. Br F Sports Med 1998;32:319-25. 8 Garraway WM, Lee AJ, Hutton SJ, et al. Impact of professionalism on injuries in rugby union. BrF Sports Med 2000;34:348-51.

9 Targett SGR. Injuries in professional rugby union. Clin $\mathcal{F}$ Sports Med 1998;8:280-5.

10 Jakoet I, Noakes TD. A high rate of injury during the 1995 Rugby World Cup. S Afr Med F 1997;87:45-7.

11 Panush RS, Inzinna JD. Recreational activities and degenerative joint disease. Sports Med 1994;17:1-5.

12 Renström PAFH. An introduction to chronic overuse Renstrom PAFH. An introduction to chronic overuse
injuries. In: Harries M, Williams C, Stanish WD, et al, eds. injuries. In: Harries M, Williams C, Stanish WD, et al, eds. Oxford textbook of sports medicin
Publications, 1998:633-48.

13 Videman T, Battié MC, Gibbons LE, et al. Lifetime exercise and disk degeneration: an MRI study of monozygotic twins. Med Sci Sports Exerc 1997;29:1350-6.

14 Armour KS, Clatworthy BJ, Bean AR, et al. Spinal injuries in New Zealand rugby union and rugby league: a twenty year survey. N Z Med f 1997;110:462-5.

15 Kew T, Noakes TD, Kettles AN, et al. A retrospective study of spinal cord injuries in Cape Province rugby players, 1963-1989. Incidence, mechanisms and prevention. S Afr Med f 1991;80:127-33.

16 Silver JR. Injuries to the spine sustained during rugby. $\mathrm{Br} F$ Sports Med 1992;26:253-8.

17 Burry HC, Calcinai CJ. The need to make rugby safer. BMF 1988;296:149-50.

18 Scher AT. Rugby injuries to the cervical spine and spinal cord: a 10-year review. Clin Sports Med 1998;17:195-206. 
19 Van Saase JLCM, Van Romunde LKJ, Cats A, et al. Epidemiology of osteoarthritis: Zoetermeer survey. Comparison of radiological osteoarthritis in a Dutch population with that 10 other populations. Ann Rheum Dis 1989;48:271-80.

20 Gardiner MJ, Altman DG. Statistics with confidence. BMJ Publishing Group: London, 1989.

21 Croce P, Gregg JR. Keeping fit when injured. Clin Sports Med 1991;10:181-95.

22 Van Mechelen W. National policies for promoting physical activity, physical fitness and better nutrition in Europe. World Rev Nutr Diet 1997;81:136-47.
23 Scher AT. Premature onset of degenerative disease of the cervical spine in rugby players. S Afr Med f 1990;77:5578.

24 Berge J, Marque B, Vital JM, et al. Age-related changes in the cervical spines of front-line rugby players. Am $\mathcal{F}$ Sports Med 1999;27:422-9.

25 Stanish WD, Wood RM. Overuse injuries of the knee. In: Harries M, Williams C, Stanish WD, et al, eds. Oxford textbook of sports medicine. Oxford: Oxford Medical Publicabook of sports medicine.
tions, 1998:679-93.

\section{Take home message}

- The most common reason given by ex-players for ceasing to play rugby was an injury sustained while playing rugby

- Only a small proportion of players suffer significant effects as a result of rugby injuries sustained four years earlier, but the impact is substantial in some cases

- This and cohorts of rugby players in other parts of the world need to be followed up for at least 20 years to assess the long term effects on health resulting from rugby injuries 